Research Article

\title{
Performance of GGBS Cement Concrete under Natural Carbonation and Accelerated Carbonation Exposure
}

\author{
Jun Zhao, ${ }^{1}$ Eskinder Desta Shumuye $\mathbb{D}^{1},{ }^{1,2}$ Zike Wang, ${ }^{3}$ and Gashaw Assefa Bezabih $\mathbb{D}^{2}$ \\ ${ }^{1}$ School of Civil Engineering, Zhengzhou University, Zhengzhou 450001, China \\ ${ }^{2}$ Department of Construction Technology and Management, Hawassa University Institute of Technology, Hawassa 05, Ethiopia \\ ${ }^{3}$ School of Mechanics and Safety Engineering, Zhengzhou University, Zhengzhou 450001, China
}

Correspondence should be addressed to Eskinder Desta Shumuye; eskdes@gmail.com

Received 3 January 2021; Revised 2 March 2021; Accepted 20 March 2021; Published 29 March 2021

Academic Editor: Hao Yi

Copyright (C) 2021 Jun Zhao et al. This is an open access article distributed under the Creative Commons Attribution License, which permits unrestricted use, distribution, and reproduction in any medium, provided the original work is properly cited.

One of the primary problems related to reinforced concrete structures is carbonation of concrete. In many cases, depth of carbonation on reinforced concrete structures is used to evaluate concrete service life. Factors that can substantially affect carbonation resistance of concrete are temperature, relative humidity, cement composition, concentration of external aggressive agents, quality of concrete, and depth of concrete cover. This paper investigates the effect of varying the proportions of blended Portland cement (ordinary Portland cement (OPC) and ground granulated blast-furnace slag (GGBS)) on mechanical and microstructural properties of concrete exposed to two different $\mathrm{CO}_{2}$ exposure conditions. Concrete cubes cast with OPC, and various percentages of GGBS $(0 \%, 30 \%, 50 \%$, and $70 \%)$ were subjected to natural (indoor) and accelerated carbonation exposure. The aim of this paper is to present the research findings and authenticate the literature results of carbonation by using GGBS cement in partial replacement of OPC. The concretes with OPC are compared to concretes with various percentages of GGBS, to assess the carbonation depth as well as rate of carbonation of GGBS-based concretes, under both accelerated carbonation and natural carbonation exposure conditions. Even though GGBS cement increases the carbonation depth, the results are not the same with different GGBS replacement percentages. A correlation is made between concrete samples exposed to $15 \pm 2 \%$ carbon dioxide $\left(\mathrm{CO}_{2}\right)$ concentration and those exposed to natural $\mathrm{CO}_{2}$ concentration. The results reveal that the products formed by carbonation are similar under both exposure conditions. The experimental tests also revealed that GGBS cement concrete has a lower carbonation resistance than OPC concrete, due to the consumption of portlandite by the pozzolanic reaction. The combination of $70 \%$ OPC and 30\% GGBS behaved well enough with respect to accelerated carbonation exposure, the depth of carbonation being roughly equivalent to that of control group $(100 \%$ OPC). The results also show that rate of carbonation becomes more sensitive as the percentage of GGBS replacement increases (binder ratio), rather than duration of curing. Concretes exposed to natural carbonation (indoor) achieved lower carbonation rates than those exposed to accelerated carbonation.

\section{Introduction}

The process of Portland cement production is energy intensive, releasing a huge amount of $\mathrm{CO}_{2}[1,2]$, both of which are likely to have a significant impact on the environment. According to Sanjuan et al. (2020), Sanjuan et al. (2019), and Mo and Panesar [3-5], the production of cement was responsible for about $7.4 \%, 6.7 \%$, and $5 \%$ of the global $\mathrm{CO}_{2}$ emission, respectively. On the other side, some studies have been conducted to find the carbonation uptake in order to verify a better carbonation emission balance. Given that, the calcium oxide in cementitious materials is not stable over time, and the hydration products gradually reabsorb atmospheric carbon dioxide as a result of carbonation process $[3,6,7]$. For instance, 8.7 million tons of carbon dioxide were found to be up taken by mortars and concretes made with Portuguese cement over a ten-year period, in which 37.8 million tons were released due to the calcination process [3]. Sanjuan et al. further reported that 31 million tons of carbon dioxide were found to be up taken by mortars and concretes made with the Spanish cement industry from 2005 to 2017 [8]. A worldwide study has anticipated a carbon dioxide uptake of $43 \%$ of the cumulative $\mathrm{CO}_{2}$ emission from the production of Portland cement by concrete and mortar from 1930 to 2013 [6]. Thus, 
solutions need to be implemented to decrease its impact on the environment. Supplementary cementitious materials (SCMs) are progressively being used in the construction industry to reduce the OPC content. Use of SCMs improves concrete durability and has environmental and economic advantages $[3,5,7,9]$. However, it is critical to understand the long-term performance and durability of these materials in order to maximize the service life of the structure. Apart from considerably reducing the service life of an RC (reinforced concrete) structure, great deal of expenditure is also spent on renovation and restoration work $[10,11]$. The intensity of steel corrosion due to carbonation depends on the environmental conditions and weather, in particular temperature, relative humidity, nature and concentration of the external aggressive agents, quality of concrete, and depth of concrete cover [10-13]. Hence, considering the effect of $\mathrm{CO}_{2}$ (carbonation) during the evaluation of the durability of concrete structure is vital $[14,15]$.

Carbonation and chloride ion ingress are the two major processes that cause the corrosion of a reinforced structure [11]. The prime cause of deterioration is corrosion of the steel reinforcement in the concrete structure [16]. Carbonation of concrete is a complex physical and chemical process. Summaries of the chemical reactions in the carbonation process can be found in Villain et al. [17] and Kurda et al. [18], amongst others. In brief, carbonation begins at the surface of the concrete by penetration of $\mathrm{CO}_{2}$. After diffusion of the gas into the concrete, the carbon dioxide $\left(\mathrm{CO}_{2}\right)$ first dissolved in the pore solution and then reacts with the $\mathrm{OH}^{-}$, forming $\mathrm{CO}_{3}{ }^{2-}$. Consequently, a drop in the $\mathrm{pH}$ of the concrete pore solution occurs. When the solubility of portlandite $\left(\mathrm{Ca}(\mathrm{OH})_{2}\right)$ reaches $\mathrm{pH}$ of 12.5 , the precipitation of calcium carbonate $\left(\mathrm{CaCO}_{3}\right)$ starts according to the reactions given in equations (1)-(3), the concentrations depending on the $\mathrm{pH}$ of the pore water solution, the ambient $\mathrm{CO}_{2}$ concentration, the presence of other solutes in the pore water, particularly the alkalis $\left(\mathrm{Ca}(\mathrm{OH})_{2}\right)$, and humidity [19-22]. High carbonation rate was observed when the concrete exposed at $50-70 \%$ relative humidity [2]. By Henry's law, the $\mathrm{CO}_{2}$ in the pore air is directly proportional to the concentration of $\mathrm{CO}_{2}$ in the pore water. At higher $\mathrm{CO}_{2}$ concentrations, more $\mathrm{CO}_{2}$ molecules reach the carbonation front within a given time, dissolve, and dissociate, and more calcium can react to form calcium carbonate. This reaction increases the dissolution rate of the calcium from the hardened cement paste constituents into the water. Thus, the calcium supply that can react is reduced faster and the carbonation front progresses faster [23]:

$$
\begin{aligned}
\mathrm{CO}_{2}+2 \mathrm{OH}^{-} & \longleftrightarrow \mathrm{CO}_{3}^{2-}+\mathrm{H}_{2} \mathrm{O} \\
\mathrm{Ca}(\mathrm{OH})_{2} & \longleftrightarrow \mathrm{Ca}^{2+}+2 \mathrm{OH}^{-} \\
\mathrm{CO}_{2}+\mathrm{Ca}(\mathrm{OH})_{2} \downarrow 2 \mathrm{OH}^{-} & \longleftrightarrow \mathrm{Ca}^{2+}+\mathrm{CO}_{3}^{2-}+\mathrm{H}_{2} \mathrm{O} \\
& \longleftrightarrow \mathrm{CaCO}_{3} \downarrow+\mathrm{H}_{2} \mathrm{O} .
\end{aligned}
$$

Results obtained by Bakharev et al., after concrete exposure for 120 days to accelerated carbonation $\left(10-20 \% \mathrm{CO}_{2}\right.$ and $70 \%$ relative humidity $(\mathrm{RH})$ ), show that the carbonation depth increased more for AAS (alkali-activated slag) than in OPC concrete specimens [24]. The results also showed that strength cutback and carbonation depth remained greater in AAS than in OPC concrete samples. From the experimental results, compressive strength improved for OPC concrete samples. These results were in agreement with the work of Behfarnia and Rostami [25], who observed that as the compressive strength increases, the carbonation depth gradually decreases. This also supports the evidence that alkali-activated slag concrete has a lower resistance against $\mathrm{CO}_{2}$ penetration than ordinary Portland cement concrete.

$\mathrm{Li}$ and $\mathrm{Li} \mathrm{[26]} \mathrm{examined} \mathrm{the} \mathrm{carbonation} \mathrm{resistance} \mathrm{of} \mathrm{fly}$ ash (FA) and blast-furnace slag (BFS)-based geopolymer concrete and concluded that the carbonation resistance of this concrete cured at room temperature is lower than concrete cast from OPC. Moreover, concrete with a greater strength tends to have a higher carbonation resistance. Andrade [27] studied the degree of carbonation on two different classes of concrete $(0.6$ and $0.45 \mathrm{w} / c)$ under three different environmental exposure conditions (indoors, outdoors sheltered from rain, and exposed outdoor unsheltered) for almost 4 years using fifteen different proportions of cementitious materials. It is clear that the pozzolanic reaction is slower than that of Portland cement hydration. The results showed that with increases in the content of GGBS mineral, the carbonation rate also increases. In addition, the greatest carbonation depth was recorded in samples cured outdoors and unsheltered from rain. Due to the relatively low relative humidity, low carbonation rate was recorded in samples cured indoors.

Otieno et al. [10] investigated the effect of concrete quality, environmental exposure and duration of initial moist curing on carbonation rate of concrete exposed to urban, inland environment. They found that carbonation rate is more sensitive to concrete quality than duration of curing [28]. They also noted that indoor exposed specimens showed higher rate of carbonation compared to outdoor exposed concretes, due to the higher concentration of $\mathrm{CO}_{2}$ in the case of indoor exposure. In addition, $\mathrm{CO}_{2}$ concentration is a more determining factor than $\mathrm{RH}$, and a higher rate of carbonation is observed in blended Portland cement than OPC concretes. Various factors appear to affect the porosity of carbonated OPC and blended Portland cement during the carbonation process. The $\mathrm{CO}_{2}$ pressure, surrounding temperature and relative humidity, carbonation exposure duration, and aggregate moisture condition seem to be the predominant factors of carbonation [29].

However, the investigation of carbonation has been mostly carried out under ambient, or close to ambient, atmospheric pressures, and different carbonation duration and concentration in most of the existing literature. Mo [30] reported on the effect of accelerated carbonation and performance of concrete made with steel slag as binding materials, and aggregates with $60 \%$ of steel slag powders containing high free-CaO content, $20 \%$ of Portland cement, and up to $20 \%$ of reactive magnesia and lime. They showed that the carbonated concrete mortar matrix appears to be denser, due to the formation of calcite resulting from 
carbonation. Compared to steel slag concrete cured under conventional moisture curing for $28 \mathrm{~d}$, the compressive strength of concrete specimens $\mathrm{CO}_{2}$ curing was significantly increased. Despite that, there is a lack of information about the change in microstructure of concrete with slag cement after carbonation exposure. To rectify this knowledge gap, this study investigates the effect of using GGBS as cement replacement in different proportions, and under two carbon dioxide exposure conditions (accelerated carbonation and natural), on mechanical and microstructural properties of blended Portland cement.

In addition, the carbonation resistance of GGBS cement concrete is investigated, and the effects of slag cement replacement level and duration of curing on carbonation rate and depth are addressed. Finally, the outcome of concrete carbonation on the pore structure of OPC and GGBS concrete is discussed.

\section{Experimental Details}

2.1. Raw Materials. Type I ordinarily Portland cement (OPC), of PO $42.5 \mathrm{R}$ and as stated by ASTM-C989-09 Chinese made slag cement type S-95 (42.5 MPa), complying with Chinese standard specification (GB175 and GB/ T18046) [31], was used in the preparation of the concrete specimens. Table 1 shows the chemical composition of the OPC and GGBS used in the study. Crushed granite with a maximum size of $10 \mathrm{~mm}$, specific gravity of 2.60 was used as coarse aggregate. Natural river sand with a specific gravity of 2.56 was used as fine aggregate.

2.2. Specimen Preparation. Different slag cement replacement percentages $(0 \%, 30 \%, 50 \%$, and $70 \%)$ were employed to prepare concrete specimens. The mixing ratios of raw materials are given in Table 2. The concrete mixture was cast on each specified mold, and then concrete specimens were sealed with polyethylene plastic covers and were left to dry for about 1 day. Subsequently, the samples were demolded and stored in the standard curing condition at a constant temperature of $20 \pm 2^{\circ} \mathrm{C}$, complying with ASTM C09 Committee 2001a and 95\% relative humidity (RH) for $28 \mathrm{~d}$. Concrete samples were taken immediately after curing for each testing date after specified carbonation period and concrete sample for morphology and microstructural investigation, then immersed in anhydrous alcohol to reduce further cement hydration for the next microstructural and mineralogical analysis. The curing process for the two-exposure conditions is mentioned in detail in Section 2.3.4. For each concrete mixture, a revolving drum pan mixer with a capacity of $60 \mathrm{~L}$ was used for the tests:

(i) Compressive strength (96 concrete cubes with size $100 \times 100 \times 100 \mathrm{~mm})$

(ii) Natural carbonation (48 concrete cubes with size $100 \times 100 \times 100 \mathrm{~mm}$ )

(iii) Accelerated carbonation (48 concrete cubes with size $100 \times 100 \times 100 \mathrm{~mm}$ )
TABLE 1: Chemical composition and specific gravity of cement and GGBS (\%wt.).

\begin{tabular}{|c|c|c|}
\hline Component (\%) & $\mathrm{OPC}$ & GGBS \\
\hline $\mathrm{SiO}_{2}$ & 17.945 & 26.713 \\
\hline $\mathrm{Al}_{2} \mathrm{O}_{3}$ & 4.465 & 14.748 \\
\hline $\mathrm{Fe}_{2} \mathrm{O}_{3}$ & 3.558 & 0.472 \\
\hline $\mathrm{CaO}$ & 64.562 & 43.093 \\
\hline $\mathrm{MgO}$ & 3.751 & 10.145 \\
\hline $\mathrm{Rb}_{2} \mathrm{O}$ & 0.005 & 0.000 \\
\hline $\mathrm{Na}_{2} \mathrm{O}$ & 0.178 & 0.380 \\
\hline $\mathrm{K}_{2} \mathrm{O}$ & 1.176 & 0.346 \\
\hline $\mathrm{MnO}$ & 0.059 & 0.260 \\
\hline $\mathrm{TiO}_{2}$ & 0.261 & 0.662 \\
\hline $\mathrm{P}_{2} \mathrm{O}_{5}$ & 0.064 & 0.010 \\
\hline $\mathrm{NiO}$ & 0.005 & 0.003 \\
\hline $\mathrm{ZnO}$ & 0.060 & 0.000 \\
\hline Specific gravity & 3.45 & 2.94 \\
\hline LOI & 3.05 & 0.24 \\
\hline
\end{tabular}

TABLE 2: Mixing proportions of concrete samples per cubic meter.

\begin{tabular}{lcccc}
\hline \multirow{2}{*}{ Materials } & \multicolumn{4}{c}{ Mixture designation } \\
& G70 & G50 & G30 & G0 \\
\hline Cement $(\mathrm{kg})$ & 129.3 & 215.5 & 301.7 & 431 \\
GGBS $(\mathrm{kg})$ & 301.7 & 215.5 & 129.3 & - \\
Water $(\mathrm{kg})$ & 202.7 & 201.7 & 202.7 & 202.7 \\
W/c & 0.47 & 0.47 & 0.47 & 0.47 \\
Coarse aggregates $(\mathrm{kg})$ & 1052.6 & 1052.6 & 1052.6 & 1052.6 \\
Fine aggregates $(\mathrm{kg})$ & 755.2 & 755.2 & 755.2 & 755.2 \\
\hline
\end{tabular}

It should be noted that the size of concrete specimens for carbonation depth measurement was $100 \times 100 \times 100 \mathrm{~mm}$ cubes. This was chosen based on space constraints in the accelerated carbonation chamber (ACC) and also to comply with RILEM recommendation CPC-18, which states that the minimum dimension of the concrete cube should be at least 3 times greater than the maximum size of aggregate [32].

\subsection{Testing Methods}

2.3.1. Compressive Strength. The compressive strength of concrete cube specimens was measured with a loading rate of $0.05 \mathrm{MPa} / \mathrm{s}$ until the concrete specimens reached rupture point. The strength measurements of concrete cubes were done at $3,7,28$, and 56 days exposure in the accelerated carbonation chamber and at 7, 28, and 56 days exposure under natural carbonation. Three specimens were tested for each concrete mix proportion, and the average value was taken as the compressive strength of the concrete specimens.

2.3.2. Scanning Electron Microscopy (SEM). SEM was employed to investigate the morphology of both concrete specimens exposed under accelerated and natural carbonation. Granulated and powdered samples were extracted from the carbonated front of the specimens. These were placed in an oven at $50^{\circ} \mathrm{C}$ for $24 \mathrm{~h}$ to dry before microstructural analysis. An SU3800 scanning electron 
microscope with an accelerating voltage of $30 \mathrm{kV}$ with a working distance of $5 \pm 2 \mathrm{~mm}$ was used. To avoid signal intrusion, samples were coated with silver.

\subsubsection{Energy Dispersive X-Ray Spectroscopy (EDS) Analysis.} After the scanning electron microscopy (SEM) analysis, the specimens were then analyzed by EDS in order to compute some of the hydrated, carbonated phases and identify the change in hydration product of carbonated concrete specimens.

2.3.4. Carbonation Resistance. The carbonation test was carried out based on the test standard of long-term performance and durability of ordinary concrete (GBJ 82-85 standard) and (modified one GBT 50082-2009 standard) $[33,34] .96$ concrete cube specimens with size $100 * 100 * 100 \mathrm{~mm}$ were used. After 28 days curing period, in order to ensure proper $\mathrm{CO}_{2}$ diffusion during carbonation curing, the concrete specimens were removed from the wet curing chamber and dried for $48 \mathrm{~h}$ at a temperature of $60^{\circ} \mathrm{C}$ to evaporate the existing free water in the concrete pore structure [35]. All sides of the concrete cubes except for opposite casting faces of the cube are the only faces that are not painted as shown in Figures 1 and 2 to facilitate uniaxial direction carbonation. Then, the concrete samples were placed in the carbonation chamber with a $\mathrm{CO}_{2}$ concentration of $15 \pm 5 \%$, a temperature of $21 \pm 2{ }^{\circ} \mathrm{C}$, and a relative humidity of $70 \pm 5 \% \mathrm{RH}$ as shown in Figure 2. Natural and accelerated tests were carried out in separate environments. The natural carbonation experiments were carried on specimens in the natural laboratory indoor environment. The specimens subjected to accelerated carbonation were placed in a carbonation chamber at $70 \pm 5 \% \mathrm{RH}$, with $15 \% \pm 5 \% \mathrm{CO}_{2}$ content (refer Table 3).

Concrete samples were positioned evenly inside the chamber to allow uniform $\mathrm{CO}_{2}$ gas distribution throughout the chamber. For each concrete batch, three specimens were tested after $3,7,28$, and 56 days in the case of the accelerated carbonation test, and after 7, 150,180, and 365 days in the case of the natural carbonation test. The concrete cubes were removed from the carbonation chamber on each testing date, and the cube specimens were split into half using a hydraulic compression machine. Dust and loose particles were removed from exposed surface with a soft-barb brush (Figures 1 and 2).

The carbonation depths were measured at each testing date by spraying a $\mathrm{pH}$ indicator solution $(0.1 \mathrm{~g}$ phenolphthalein in $100 \mathrm{ml} 95 \%$ ethanol) onto the concrete surface which has been cleaned of dust (Figure 2), incompliance with RILEM CPC-18 [36]. To clearly differentiate the transition zone between carbonated and noncarbonated zones of concrete, it is necessary to leave the concrete specimens for a while after spraying phenolphthalein. Phenolphthalein is a colorless acid indicator which turns reddish when the $\mathrm{pH}$ value is above 9.5. If no coloration is shown, carbonation has taken place and the depth of the carbonation can be determined. Data reported are the average of 8 readings made on each face.
After samples were exposed to the two different carbonation conditions for different time periods as specified in above, samples were removed and split into two pieces and each piece was measured individually. A $1 \%$ solution of phenolphthalein in alcohol was sprayed on the broken dry concrete surface. Maximum and minimum depth of carbonation was recorded. A mean depth was also determined, and results of concrete carbonation with respect to its effect on GGBS cement replacement, curing period, and rate of carbonation are presented in the following sections.

\section{Results and Discussion}

3.1. Effect of Carbonation and Slag Replacement on Compressive Strength. Compressive strength measurement of concrete cast with OPC and GGBS, exposed to accelerated and natural carbonation, was carried out as specified in Section 2.3.4. The effect of carbonation on the compressive strength of OPC concrete with various amounts of GGBS replacement over the time of $\mathrm{CO}_{2}$ exposure and two different exposure condition is shown in Figure 3. The results show that after 7 days, the compressive strength of all the concrete specimens with various percentages of replacement of GGBS shows a slight increase in strength with increasing $\mathrm{CO}_{2}$ concentration, except for the concrete mix with $30 \%$ OPC and 70\% GGBS (G70), which shows insignificant change. The control group (0\% GGBS), G30 (30\% GGBS), and G70 (70\% GGBS) exposed to ACC had attained an 8.9, 0.6 , and $0.3 \%$ increment compared with concrete exposed to natural carbonation, respectively. Previously, two theoretical explanations were proposed to explain the strength reduction. The first reason is due to a low rate of $\mathrm{CaCO}_{3}$ crystallization during the carbonation process to fill the voids in the pore structure. The presence of $\mathrm{CH}$ and ettringite as sources of $\mathrm{Ca}^{2+}$ for $\mathrm{CaCO}_{3}$ formation was regarded as one of the reasons for strength reduction. Moreover, $\mathrm{CaCO}_{3}$ development can be inhibited by low $\mathrm{Ca} / \mathrm{Si}$ of $\mathrm{C}-\mathrm{S}-\mathrm{H}$ in hardened slag-blended Portland cement [37]. In line with the results of this study, there seems to be a correlation between carbonation depth and compressive strength of slag-blended Portland cement. As Figure 3 shows, there is an inverse relationship between the results of compressive strength and carbonation depth of the concrete specimens. As the compressive strength increases, the carbonation depth slowly decreases. This result was confirmed by $[13,26,38]$.

The compressive strength of blended Portland cement concrete can be significantly improved by carbonation [39]. This is related to the reduction in porosity and likely also changes in the $\mathrm{C}-\mathrm{S}-\mathrm{H}$ gel structure as the main binding component in cement [40]. Although some researchers suggest this is not the case for blended Portland cement [24]. Bakharev [24] explained that during calcite crystallization, an increased porosity founded. Consequently, it is believed that because of carbonation, the concrete permeability is possibly increased, whereas the concrete strength is reduced [24]. Li et al. [37] also showed that conversely, the carbonation had an adverse effect on AAS mortar strength [37]. This effect is due to the carbonation of the pozzolanic C-S-H 


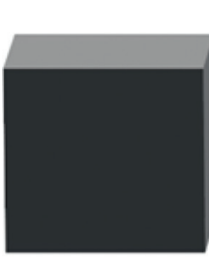

(a)

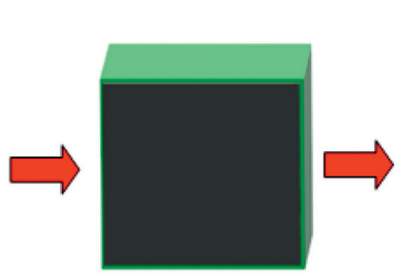

(b)

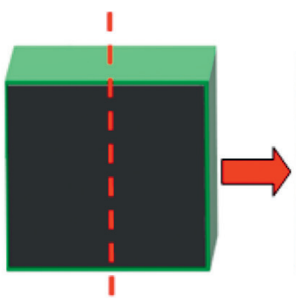

(c)

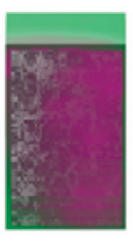

(d)

Figure 1: Carbonation test setup: (a) uncoated concrete surfaces; (b) all surfaces, except one, are coated; (c) specimens are sectioned into half; (d) phenolphthalein solution was sprayed on the fresh saw surface, and carbonation depth reading was taken.

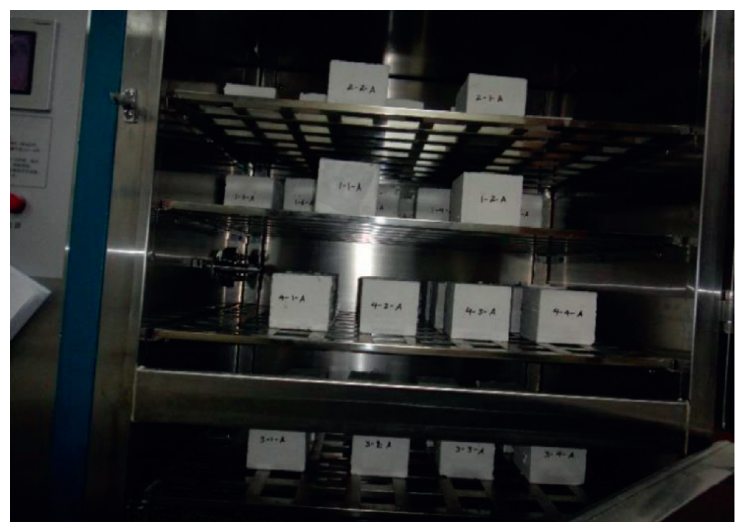

(a)

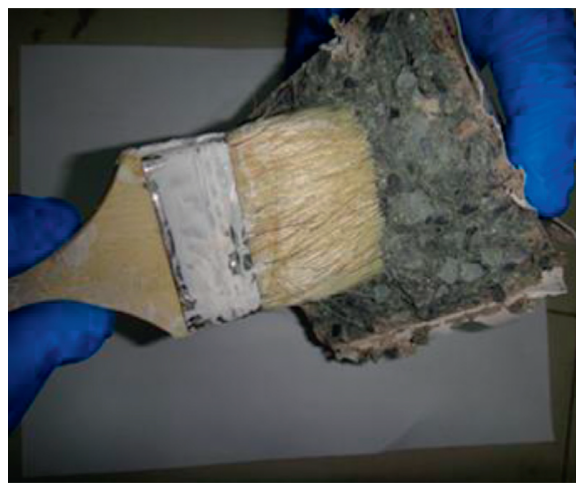

(c)

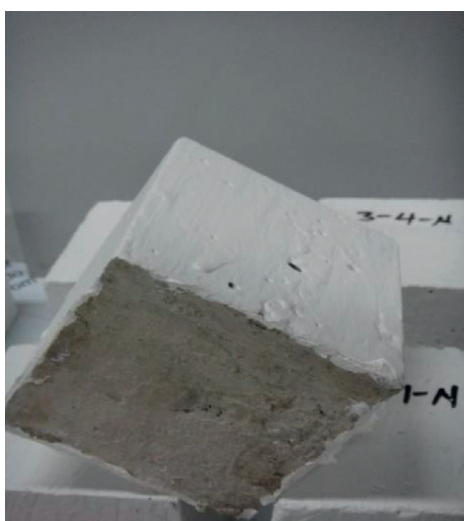

(b)

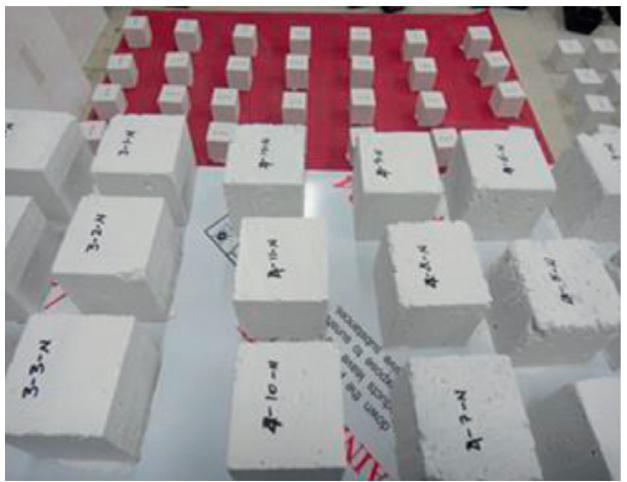

(d)

FIgURE 2: (a) Accelerated carbonation chamber. (b) Coated concrete sample. (c) Removing unwanted dust. (d) Concrete cubes after coating.

TABLE 3: Environmental conditions during the carbonation test period.

\begin{tabular}{lcc}
\hline & ACC & Indoor \\
\hline Temperature $\left({ }^{\circ} \mathrm{C}\right)$ & $21 \pm 2{ }^{\circ} \mathrm{C}$ & $10-41{ }^{\circ} \mathrm{C}$ \\
RH $(\%)$ & $70 \pm 5 \%$ & $25-69 \%$ \\
{$\left[\mathrm{CO}_{2}\right]$ in air } & $15 \pm 5 \%$ & $300-500(\mathrm{ppm})$ \\
\hline
\end{tabular}

and $\mathrm{C}-\mathrm{H}$, which may produce a poorly hydrated calcium silicate gel of a low molar volume. As a result, a great amount of water, which is initially chemically bound within the C-S$\mathrm{H} / \mathrm{C}-\mathrm{H}$, is released from the calcium silica gel resulting in extra pore space in the concrete microstructure [41]. This unusual behavior by the mineral admixture (GGBS) is more evident with high-volume replacement percentage $70 \%$, and that carbonation can then considerably contribute to an increase in porosity. In the current investigation, the compressive strength of Portland cement concrete is significantly improved by carbonation, whereas for high-volume slag-blended Portland cement concrete specimens, a reduction in compressive strength was observed. The results are consistent with the previous studies [25, 37, 42, 43].

The changes in compressive strength tends to be stay steady after $28 \mathrm{~d}$ of $\mathrm{CO}_{2}$ exposure for the blended Portland cement. Concrete with high percentage of GGBS cement replacement experiences lower mechanical strength than that of OPC concrete, but the strength declines at a slower rate over time, and the long-term strength is excellent. This 


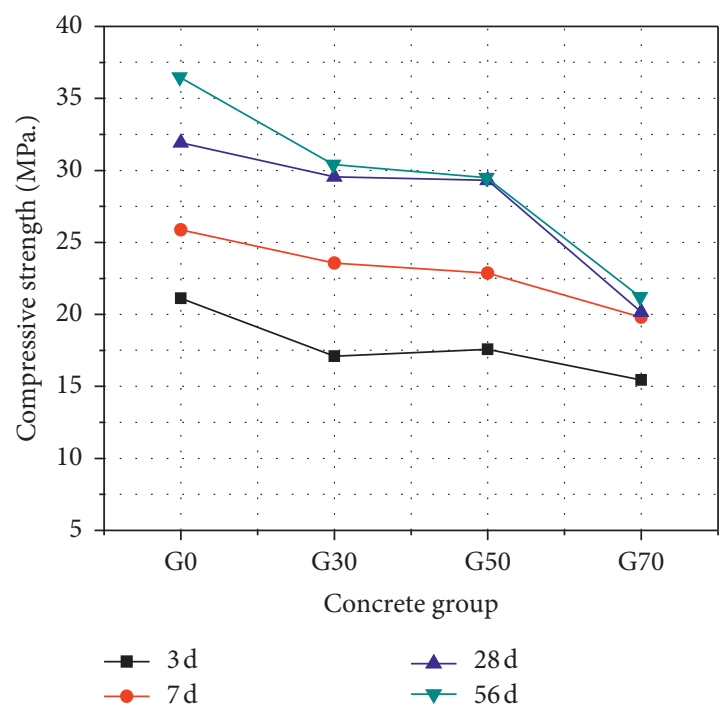

(a)

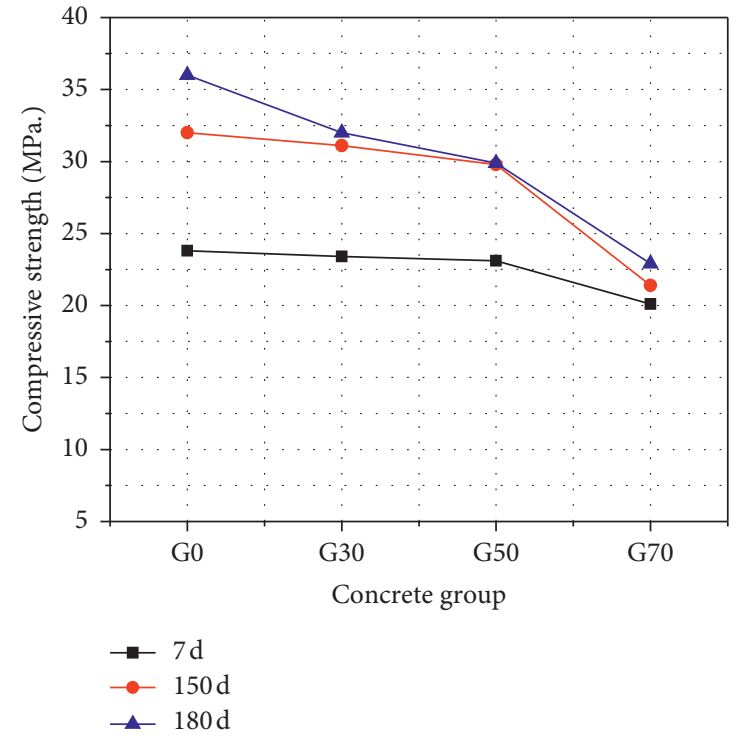

(b)

FIGURE 3: Influence of (a) accelerated carbonation and (b) natural carbonation on compressive strength of concrete with different cement replacement.

feature becomes more pronounced as the extent of replacement increases. In general, in the early days of GGBS cement concrete carbonation, the amount of pores inside the concrete increases; however as the hydration progresses, the number of capillary pores with relatively larger diameters decreases; if the finesse of slag cement particle is not more fine-grained than Portland cement, the carbonation depth would be more intensified.

\subsection{Influence of GGBS Replacement Ratio on the Carbonation} Depth of Concrete. Carbonation depth of OPC with several slag cement replacement ratios and different rates of carbonation exposure and curing time are illustrated in Figures 4, 5, and 6. It can be seen that depth of carbonation at every time increases significantly with increasing slag cement replacement: $30 \%, 50 \%$, and $70 \%$ which are $5.73 \%$, $7.30 \%$, and $135.29 \%$ of the control concrete group $(100 \%$ OPC) at $28 \mathrm{~d}$ for accelerated carbonation curing exposure, respectively. As seen in Figure 4, no concrete groups showed any visible carbonation that could be detected by phenolphthalein after 7 days of the natural carbonation test. As GGBS cement content in the concrete mixes increased, the rate of carbonation and carbonation depth also increased. After $56 \mathrm{~d}$, the depth of carbonation of sample with $70 \%$ GGBS increased by $270 \%$ compared to that of the reference concrete (100\% OPC). The same trend is seen in Figure 6 for $30 \%$ and $50 \%$ GGBS content, and carbonation depth of concrete sample at $56 \mathrm{~d}$ increases by $49.7 \%$ and $52.5 \%$, respectively. From these experimental results, we can refer that as the cement substituted by high-volume slag mineral admixture, not less than $30 \%$ of total amount of cementitious materials, the concrete internal solution alkalinity decreases with increase in mineral admixture replacement. This implies that the more OPC cement replaced by GGBS,

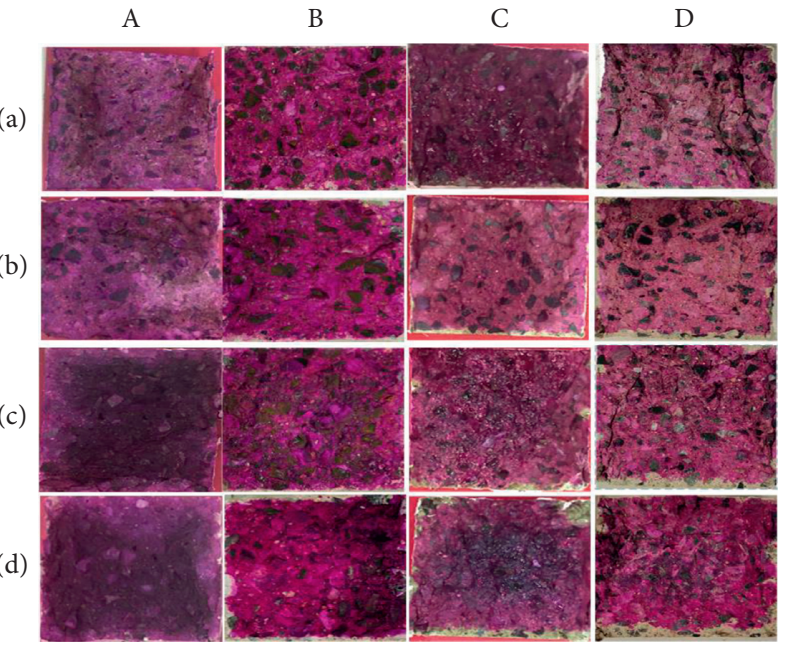

FIGURE 4: Images of concrete specimens sprayed with phenolphthalein indicator (1:100\% OPC (G0), 2: 70\% OPC (G30), $3: 50 \%$ OPC (G50), and $4: 30 \%$ OPC (G70)). Note. A B, C, and D represent 7,150 , and 180 days and 1-year exposure result for concrete groups in natural carbonation curing.

the larger the carbonation depth become. The carbonation of concrete is usually slowed down by the reaction of $\mathrm{CO}_{2}$ with Portlandite. It means that consumption of Portlandite by GGBS cement leads to an increase in the carbonation depth, especially if the permeability of the concrete is not decreased by the pozzolanic reaction [44]. Similar results were also reported by De Belie et al., Šavija and Luković, and Gao et al. [2, 40, 45]. Black [46] and Sisomphon and Franke [47] also stated that consumption of portlandite occurs by the pozzolanic reaction, thus reducing the buffering capacity of the cement paste, leading to low $\mathrm{pH}$ and so reducing resistance to carbonation. According to Black (2016) [46] at a low level 


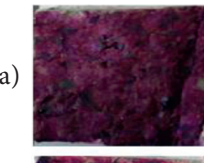

(b)

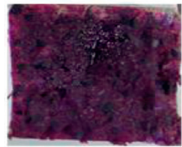

(c)

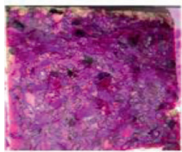

(d)

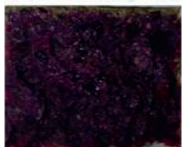

B
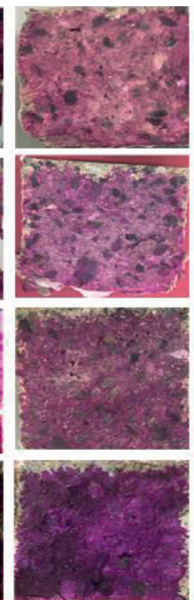

C

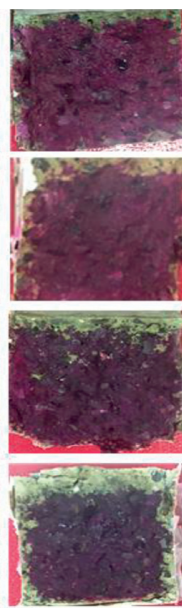

D
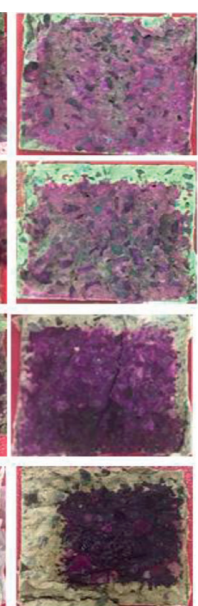

FIGURE 5: Images of concrete specimens sprayed with phenolphthalein indicator (1:100\% OPC (G0), 2:70\% OPC (G30), 3:50\% OPC (G50), and 4:30\% OPC (G70)). Note. A B, C, and D are 3-, 7-, 28-, and 56-day results for concrete groups in ACC, respectively.

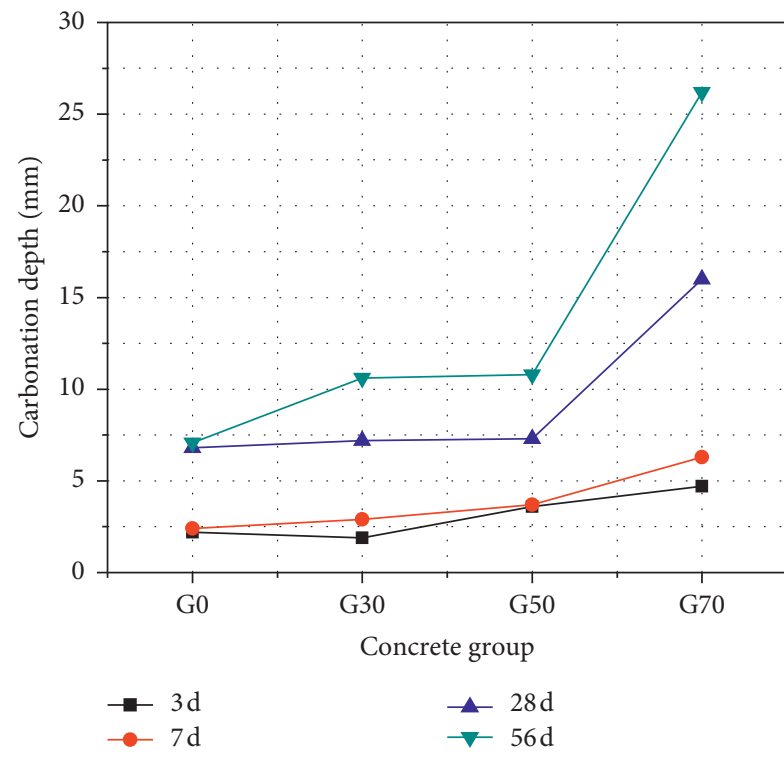

(a)

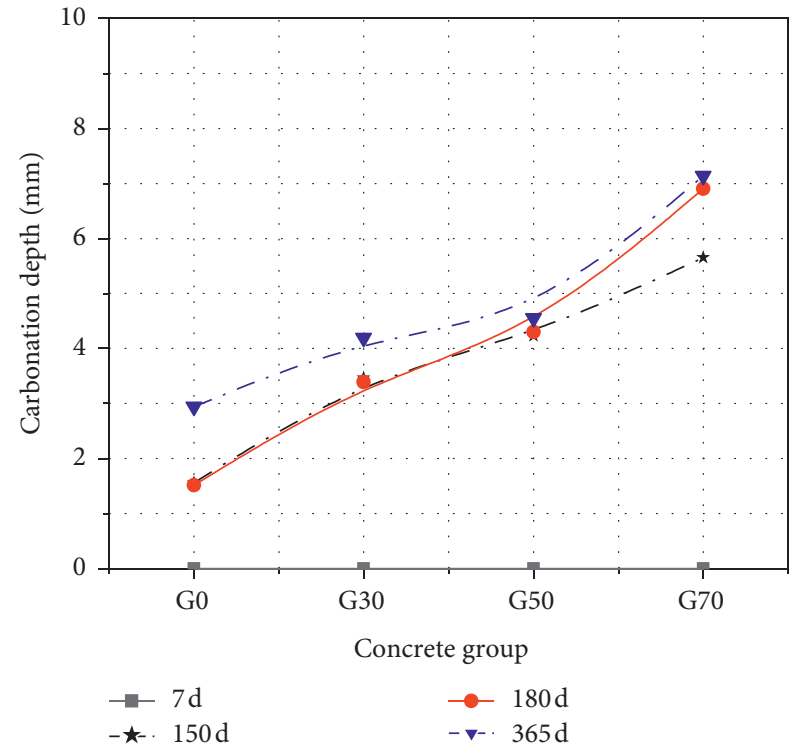

(b)

FIGURE 6: Influence of GGBS cement on carbonation resistance of concrete exposed to (a) accelerated carbonation and (b) natural carbonation.

of replacement by slag $(10 \%)$, the pozzolanic reaction reduces the permeability of the concrete, thus reducing the ingress of carbon dioxide and hindering carbonation. Conversely, at higher slag replacement levels, cement blends are more vulnerable to carbonation.

Photographs provided in Figures 4 and 5 show that for a given concrete class, slag content, and exposure duration, the indoor natural carbonation exposed concretes had lower carbonation rates than those exposed to ACC environments. This can be attributed to the higher concentration of $\mathrm{CO}_{2}$ in the ACC. From Figure 4, it can also be seen that carbonation depth of concrete for all slag replacement percentages shows insignificant carbonation depth at early stages for concretes exposed to natural carbonation. All concrete groups did not show any visible carbonation that could be detected by phenolphthalein during 7 days of natural carbonation exposure. However, after exposure in the NC (natural carbonation) test for about 150 days, slight change in carbonation depth was noted. After 5 months, carbonation depths for concrete cast from $30 \%, 50 \%$, and $70 \%$ slag cement were $121.8 \%, 171.1 \%$, and $262.17 \%$ of that of reference concrete. Note the difference in carbonation depth in the NC and ACC test, i.e., $0-5.65 \mathrm{~mm}$ versus $0-26.2 \mathrm{~mm}$, respectively. It can be seen from Figure 6 that use of OPC concrete always led to lower carbonation depths, while concrete with the higher GGBS cement replacement gave the greatest carbonation depth, both under accelerated and natural $\mathrm{CO}_{2}$ exposure 
conditions [48]. However, the current demand and high $\mathrm{CO}_{2}$ emissions during the production of OPC make it crucial to adopt blended cement with low clinker content in construction industries. Worldwide, more than $80 \%$ of cement is blended [48], and utilization of anticarbonation coatings should further be taken as a precondition to reduce the rate of carbonation and sustain structural integrity [48]. The reason is that alkaline-hydrated products (e.g., Ca $(\mathrm{OH})_{2}$ ) become less abundant with a high percentage of GGBS replacement, and the carbonation reaction in GGBS concrete mixes generates a coarsening of the pore structure which allows $\mathrm{CO}_{2}$ to infiltrate more easily into the concrete $[46,49]$. This leads to low initial alkalinity in the concrete pore solution. The same result was found by Gao et al. and Zhao et al. [45, 50]. This coarsening of the pore structure might be linked to the formation of extra silica gel due to decomposition of C-S-H [40].

Figure 7 illustrates the required concrete cover strength (cube specimen at 28 days) and concrete cover thickness for the most severe exposure conditions of carbonation environment for different codes (ACI-318 (ACI, 2011)), GB/T 50476, and Eurocode (CEN, 2000; CEN, 2004). To identify whether carbonation-initiated corrosion will cause problems in the structure within its life span, the experimental values must be compared to the minimum thickness of the concrete cover. In ACI 318 (2011) [51], the minimum thickness of the concrete covers for reinforcement is not less than $50 \mathrm{~mm}$ for wall and slab. Eurocode (EN1992-1-1) [52] and GB/T 50476-2008 [53] stipulate 25 and $15 \mathrm{~mm}$ concrete cover (applicable in XC exposure class), respectively. Given that the accelerated carbonation tests in this study were conducted at a $\mathrm{RH}$ of $70 \%$, which is favorable for carbonation, the experimental values were compared to a concrete cover thickness of $25 \mathrm{~mm}$ (applicable in a XC3 environment/moderate humidity) (see Figure 6). The carbonation depths for all concrete mixes except that cast from 30\% OPC (G70) are in acceptable range for environments containing $15 \pm 2 \% \mathrm{CO}_{2}$, in the specified $\mathrm{CO}_{2}$ exposure duration.

3.3. Influence of Carbonation Rate on the Concrete Carbonation Resistance. The concern and doubts have led to the formation of a number of different forms of the model for expressing the progress in carbonation through time as a function of various variables. Fick's law is the initiation point to determine the mathematical modeling of concrete carbonation. The diffusion flux in one-dimensional space with respect to Fick's first low is described by the following equation:

$$
Q=-D \frac{\partial \varphi}{\partial x}
$$

where $Q$ is the flow, the amount of the material flowing through a unit cross section per unit time $\mathrm{mol} / \mathrm{m}^{2} . \mathrm{s}$; D is the diffusion coefficient $m 2 / s ; \varphi$ is the concentration of the diffusing substance $\mathrm{mol} / \mathrm{m}^{3} ; x$ is the diffusion direction, $m$. Fick's second law of diffusion followed where the density of diffusion flux varies:

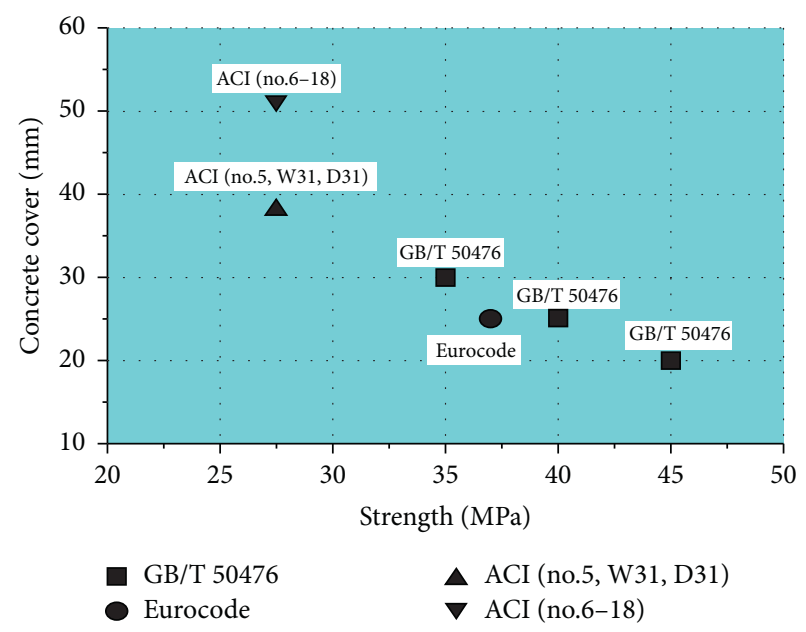

FIgURE 7: Required concrete strength and thickness of concrete cover for atmospheric environments from Eurocode, ACI-318, and GB/T $50476[54,55]$.

$$
\frac{\partial \varphi}{\partial t}=\mathrm{DF}_{D} \frac{\Delta \varphi}{x},
$$

where $t$ is the time, $F_{D}$ is the surface through where the diffusion occurs, $m^{2}$, and $\Delta \varphi / \Delta x$ is the concentration gradient on the concrete surface and on the depth $x$.

When $x$ is taken as the depth of carbonation, the concentration on the depth $x$ is 0 and then equation (5) becomes

$$
\frac{\partial y}{\partial x}=\frac{\mathrm{DF}_{D} \varphi_{e x t}}{x}
$$

where $\varphi_{\text {ext }}$ is the $\mathrm{CO}_{2}$ concentration in the air:

$$
\partial Q=a F_{D} \partial x .
$$

If we assume the diffused $\mathrm{CO}_{2}$ is completely used for carbonation, the above equation will be used.

Combining equation (6) to equation (7), the basic carbonation model is obtained after integrating over $\partial Q$. This model is adapted for this study:

$$
x=x o+\sqrt{\frac{2 D \varphi_{e x t}}{a}} \cdot \sqrt{t} .
$$

The other version of equation (8) is developed by Nilsson [56] by considering different material properties:

$$
x \mathrm{CO}_{2}=\int_{0}^{t} \frac{\varphi_{\text {ext }}}{a} \cdot \frac{1}{\int_{x=0}^{x=x \mathrm{CO}_{2}}\left(d_{x} / D \cdot F(\mathrm{RH})\right)} d_{x} .
$$

Similarly, Papadakis [57] has also developed a mathematical model that includes participation of phase other than portlandite in carbonation:

$$
x=\sqrt{\frac{2 \mathrm{Dt}\left[\mathrm{CO}_{2}\right]}{\left[\mathrm{Ca}(\mathrm{OH})_{2}\right]+3\left[\mathrm{C}_{3} \mathrm{~S}\right]+2\left[\mathrm{C}_{2} \mathrm{~S}\right]}} .
$$

The above equation developed considering that the full carbonation of concrete is not only complete consumption of $\mathrm{Ca}(\mathrm{OH})_{2}$. Though, almost all carbonation models estimate the rate of carbonation to be related to the square root of 
exposure time by the regression analysis according to Fick's second law of diffusion as described in equation (8). This describes the rate of carbonation, where " $x$ " is the depth of carbonation in $\mathrm{mm}$, " $t$ " is the time duration for carbonation in year, "C" is the rate of carbonation in $\mathrm{mm} / \mathrm{year}^{0.5}$, and " $x_{o}$ " is the initial carbonation in $\mathrm{mm}$, usually insignificant or zero $[13,58,59]$.

As shown in Figure 8, the use of GGBS cement in the concrete results in a higher carbonation rate ( $\mathrm{C}$ value) (20.94, 26.72, and $45.5 \mathrm{~mm} /$ year $^{0.5}$ ) for 30,50 , and $70 \%$ replacement of GGBS than that with pure OPC concrete $\left(17.33 \mathrm{~mm} /\right.$ year $\left.^{0.5}\right)$ during $7 \mathrm{~d}$ accelerated carbonation exposure. Furthermore, the curing time prolonged the $\mathrm{C}$ value also shows increment $(25.95,26.35$, and $57.76 \mathrm{~mm} /$ year ${ }^{0.5}$ ), respectively, than that of reference concrete $\left(24.55 \mathrm{~mm} /\right.$ year $\left.^{0.5}\right)$ at $28 \mathrm{~d}$. The SEM and EDS results reveal that concrete mixture with plenty of $\mathrm{CH}$ phase has a lower $\mathrm{C}$ value than those with the low $\mathrm{C}-\mathrm{H}$ concentration (refer Figures 9 and 10). From the experimental results, concrete with high volume of GGBS have a faster carbonation rate than reference concrete. Similar results were also presented by Zhao et al. and Borges et al. [39, 50]. The rate of carbonation for the concrete sample with $70 \%$ GGBS replacement at 28 and 56 days under accelerated carbonation curing was higher than the reference concrete (100\% OPC) sample with the same exposure conditions. In addition, the rate of carbonation is similar for the concrete samples with 50 and $30 \%$ GGBS replacement. However, the concrete with $50 \%$ GGBS replacement showed a slight increase compared to the concrete with $30 \%$ GGBS and $(100 \%$ OPC) at 3 -day early exposure. For natural carbonation, the rate of carbonation increases with increasing percent GGBS replacement [49]. The use of GGBS in the concrete results in a higher $\mathrm{C}$ value $(5.397,6.598$, and $8.814 \mathrm{~mm} /$ year $^{0.5}$ ) for 30,50 , and $70 \%$ replacement of slag than that with reference concrete $\left(2.433 \mathrm{~mm} /\right.$ year $\left.^{0.5}\right)$ during $150 \mathrm{~d}$ natural carbonation exposure.

Furthermore, as the curing time was extended to 1 year, the $C$ value also shows slight drop $(4.19,4.55$, and $7.13 \mathrm{~mm} /$ year $\left.{ }^{0.5}\right)$, respectively, than that of reference concrete $\left(2.94 \mathrm{~mm} /\right.$ year $\left.^{0.5}\right)$ for 30,50 , and $70 \%$ replacement of slag, respectively. A study by Šavija and Luković also indicated that the carbonation rate of the concrete increases with increasing volume of blast-furnace slag, and the mechanism of carbonation for high-volume Portland slag-blended cement seems to be regulated by the amount of $\mathrm{CH}$ prior to carbonation [10,40]. The increase in rate of carbonation with increasing volume of blast-furnace slag occurs regardless of owning densified pore structure of blended cement concretes due to their finer particle size and filler effect. This reveals that concrete microstructure might not be the only indicator for monitoring the rate of carbonation [10] (refer Figure 11). However, the test results contradict Dhir et al. [60] who showed that changes in cement content do not have a noticeable effect on the resistance of concrete to carbonation.

The data regarding the influence of carbonation exposure on carbonation depth, including the abovementioned parameters, the graphs in Figures 8(a) and 8(b), are plotted on
Figure 9. Considering that the coefficient of correlation for almost all concrete groups in both exposure condition is very good with the exception of concrete group G70 in natural carbonation exposure condition and there with the trendline observed can be considered as the best fit. The following points of practical relevance of the relation can be pointed out:

(i) Despite the fact that the resistance of concrete structure to carbonation decreases with GGBS content, Figure 12 also supports this [4].

(ii) For both exposure condition (natural and accelerated carbonation exposure), concrete with $30 \%$ and 50\% GGBS content develops approximately the same carbonation resistance.

(iii) Once again, the trend observed with respect to the duration of carbonation exposure with and without GGBS is generally similar for natural and accelerated carbonation exposure. Furthermore, the carbonation depth of concrete with $0 \%, 30 \%$, and $50 \%$ GGBS content after $56 \mathrm{~d}$ of accelerated carbonation exposure was almost twice that of natural carbonation exposure.

For given concrete and carbon dioxide exposure conditions, extending the duration of curing time from 3 to $56 \mathrm{~d}$ in the case of ACC and 7-360 d in the case of natural carbonation increases the carbonation rate, although a slight drop-in rate of carbonation was also recorded during natural carbonation exposure as the exposure duration prolonged (Figure 8). This is related to reduction of pore structure improvement as a result of carbonation. However, extending the carbonation exposure is not the only reason for the increase in carbonation rate. Having a small volume of GGBS seems to have a significant impact on the rate of carbonation. For instance, for the concrete group G30 (30\%GGBS), increasing the curing time from 3 to $56 \mathrm{~d}$ under ACC results in $29.0 \%$ increases in carbonation rate, whereas the increase was $29.2 \%$ for $70 \%$ GGBS. According to Roy SK (1999) [15], the recommend range of carbonation constant " $\mathrm{C}$ " for medium strength concrete $(25-30 \mathrm{Mpa})$ in outdoor and indoor exposure was $\left(2-5 \mathrm{~mm} \mathrm{yr}^{-0.5}\right)$, respectively. From the experimental results here, the carbonation constant " $\mathrm{C}$ " ranges between 0 and $9.8 \mathrm{~mm} \mathrm{yr}^{-0.5}$ for all concrete groups exposed to natural carbonation. Sanjuan [61] also published similar carbonation depth range for $0 \%$ and 50\% GGBS cement replacement. Furthermore, "C" ranges between 1.9 and $26.2 \mathrm{~mm}$ for accelerated carbonation exposure.

\subsection{Morphology and Mineralogy of the Concrete Specimens} (EDS and SEM Analysis). The SEM picture and EDS pattern show that the amount of carbonation increases with increasing GGBS replacement and $\mathrm{CO}_{2}$ concentrations. The morphology of the portlandite $(\mathrm{C}-\mathrm{H})$ and calcium silicate hydrate (C-S-H) formed in concrete samples exposed to natural carbonation, as shown by SEM imaging (Figure 10), differs consistently from concrete samples exposed to accelerated carbonation (Figure 9). The calcite crystallites in the latter can often spotted as irregular in shape (Figure 9) and become denser as the GGBS replacement increases 


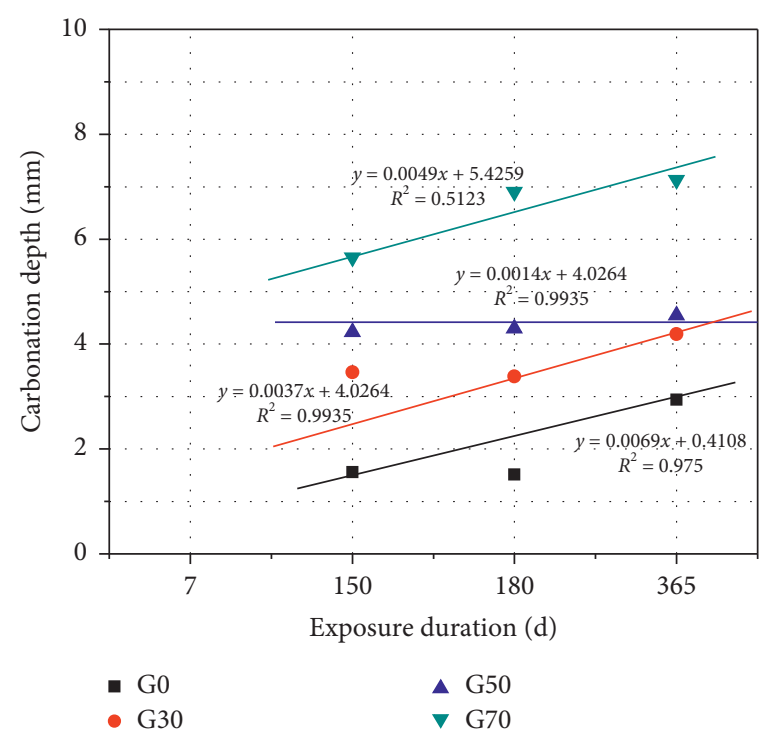

(a)

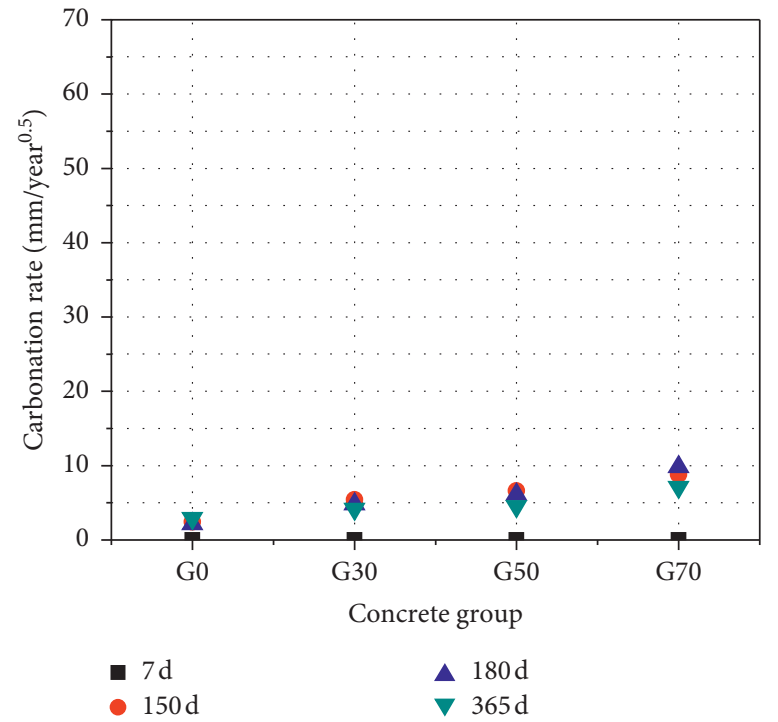

(c)

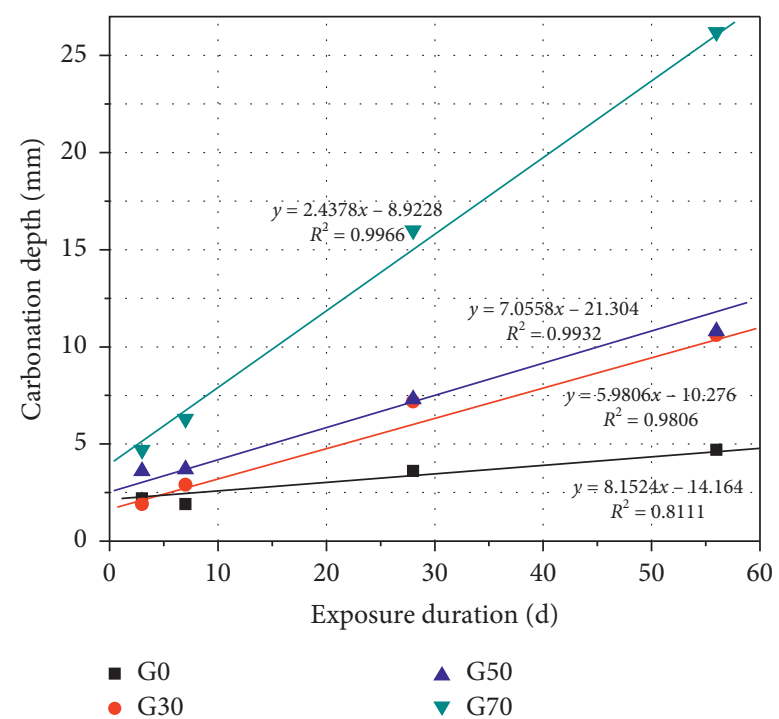

(b)

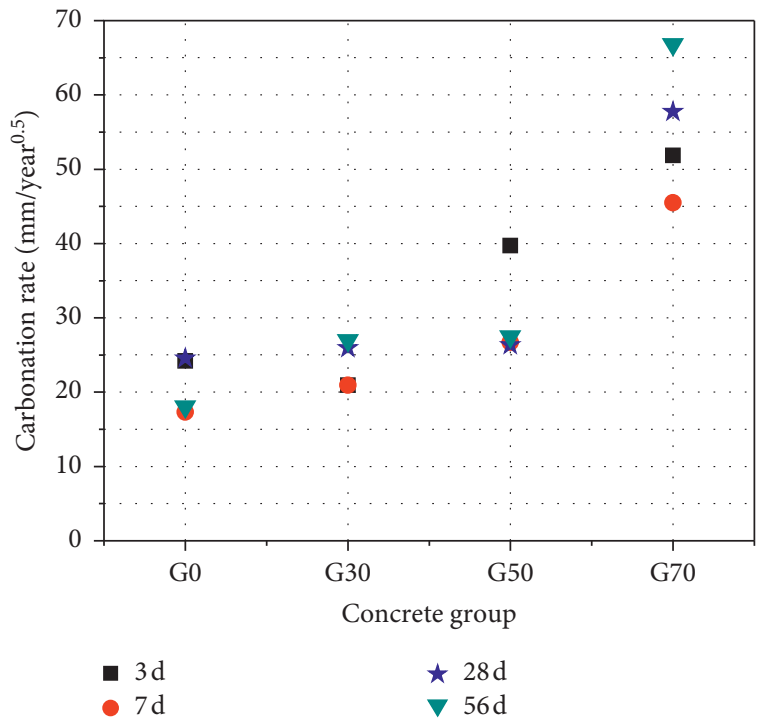

(d)

Figure 8: A typical plot of exposure duration vs carbonation depth fitting for (a) natural carbonation and (b) ACC and influence of exposure condition on rate of carbonation of concrete exposed to (c) natural carbonation and (d) accelerated carbonation.

compared to samples exposed to natural carbonation. The presence of significant calcite formation is intensified for concrete exposed to accelerated carbonation compared to natural carbonation. Increasing percentage of GGBS cement replacement leads to the formation of a coarser microstructure and a possible increase in concrete porosity. In addition, when the concrete is carbonated, the appearance of the coarser microstructure is more pronounced as the GGBS percentage increases. In high-volume GGBS cement, the reduction of the outer C-S-H porosity related to the loss of $\mathrm{CH}$ crystals replaced by a packing of calcium carbonate crystals leaves extra voids [41]. However, since the reasons for such behavior are still not well established, further study is recommended to establish guiding principles on this concept (see Figures 11 and 12).
For concrete samples exposed to natural carbonation, the inner portion of the sample can further react with increasing curing time. Angular-shaped portlandite $(\mathrm{C}-\mathrm{H})$ gel is observed in natural carbonation samples (Figure 10). The SEM data reveal that the inner section of the specimen does not change broadly during carbonation, and this section of the concrete specimen is likely responsible for further strength development. Notwithstanding, C-H reacts initially more rapidly, and its rate of reaction decreases over time, until it is overtaken by the C-S-H reaction. Carbonation of C-S-H gel results in the removal of calcium ion $\left(\mathrm{Ca}^{2+}\right)$ from the gel, causing the formation of an amorphous silica gel and various polymorphs of calcium carbonate [40]. Thus, changes in $\mathrm{C}-\mathrm{S}-\mathrm{H}$ properties by carbonation reaction can have an effect on concrete 


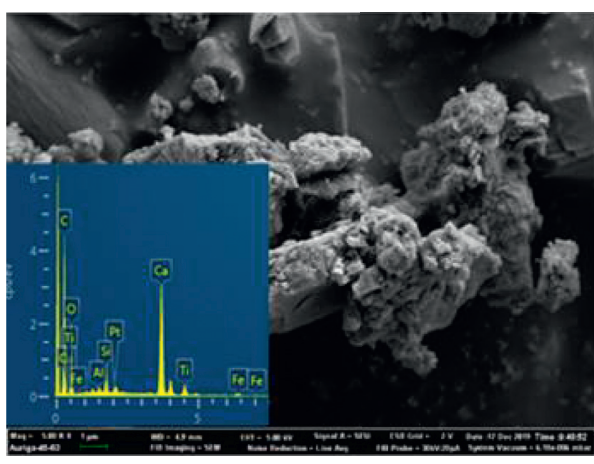

$0 \%$ GGBS (G-0)

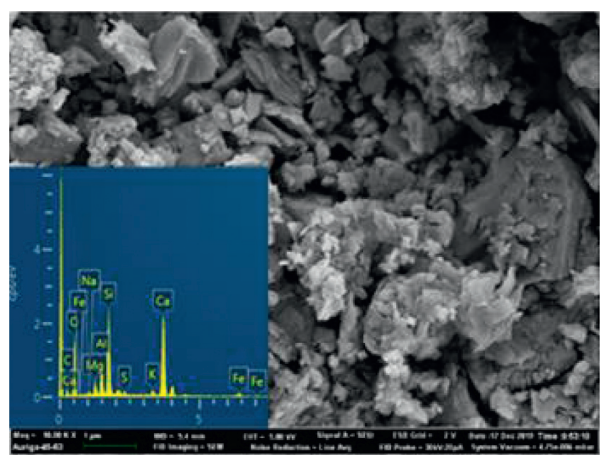

$50 \%$ GGBS (G-50)

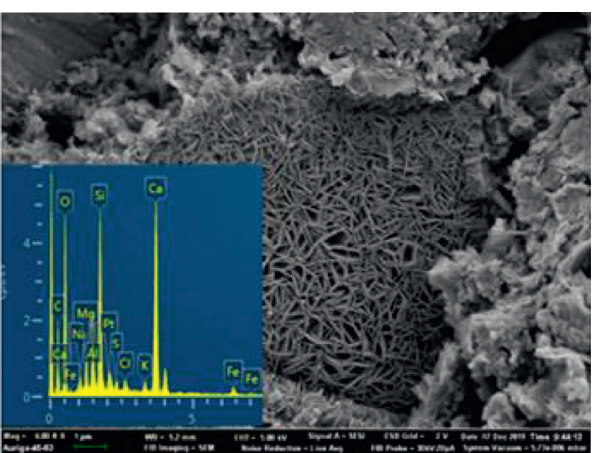

$30 \%$ GGBS (G-30)

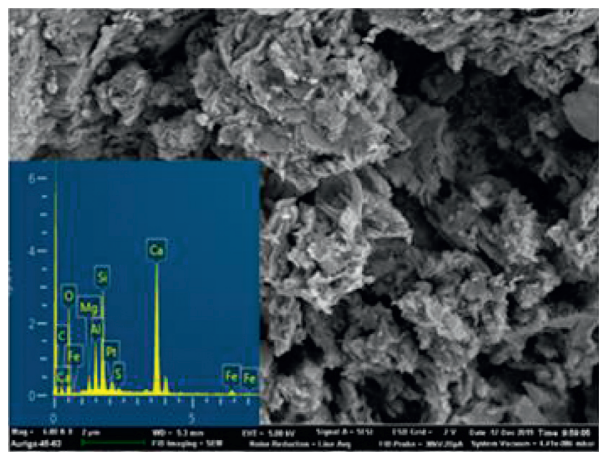

$70 \%$ GGBS (G-70)

FIGURE 9: SEM and EDS images of carbonated concrete specimens with different \%GGBS after accelerated carbonation exposure.

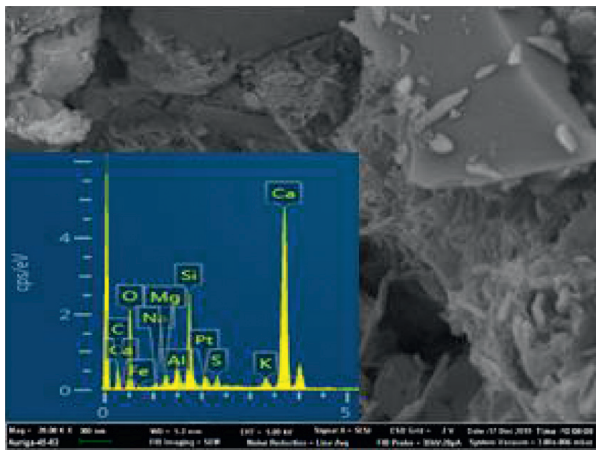

$0 \%$ GGBS (G-0)

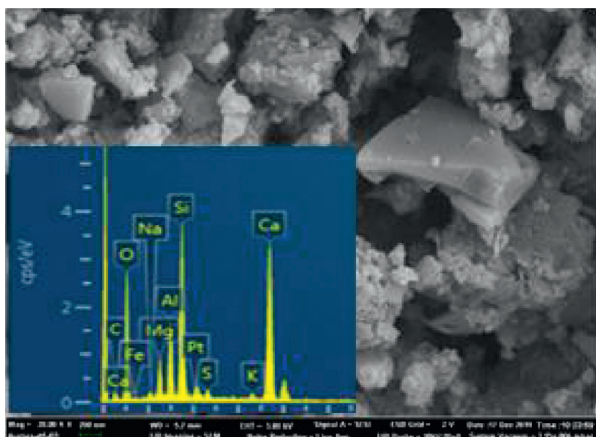

$50 \%$ GGBS (G-50)

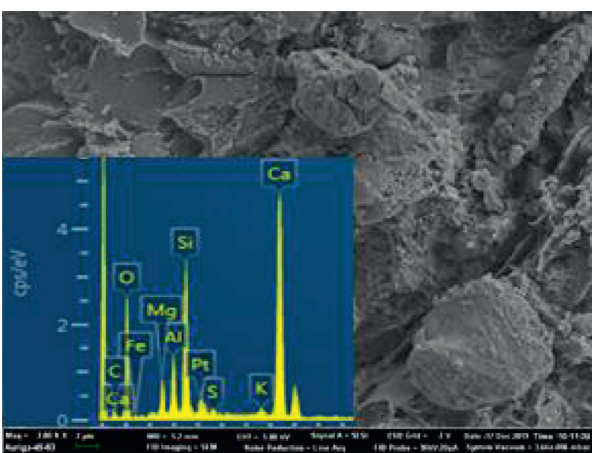

$30 \%$ GGBS $(\mathrm{G}-70)$

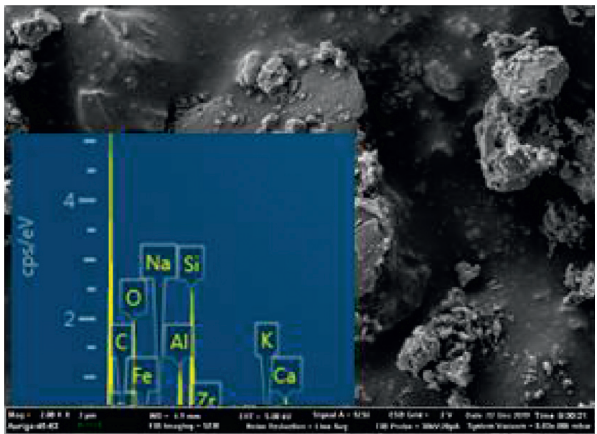

70\% GGBS (G-70)

FIGURE 10: SEM and EDS images of carbonated concrete specimens after natural carbonation exposure. 


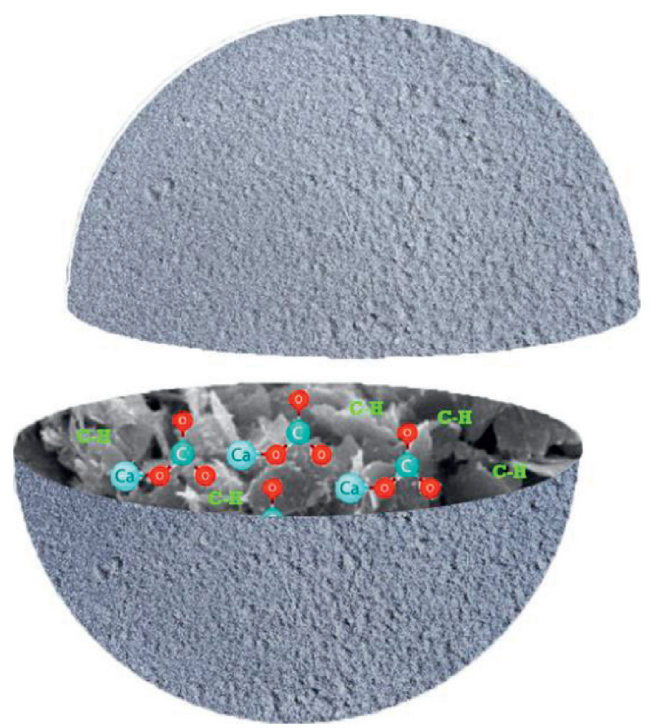

Figure 11: Concrete microstructure model with respect to $\mathrm{CaCO} 3$ formation during accelerated $\mathrm{CO} 2$ exposure in two different kinds of cement: (a) OPC and (b) high-volume GGBS cement.

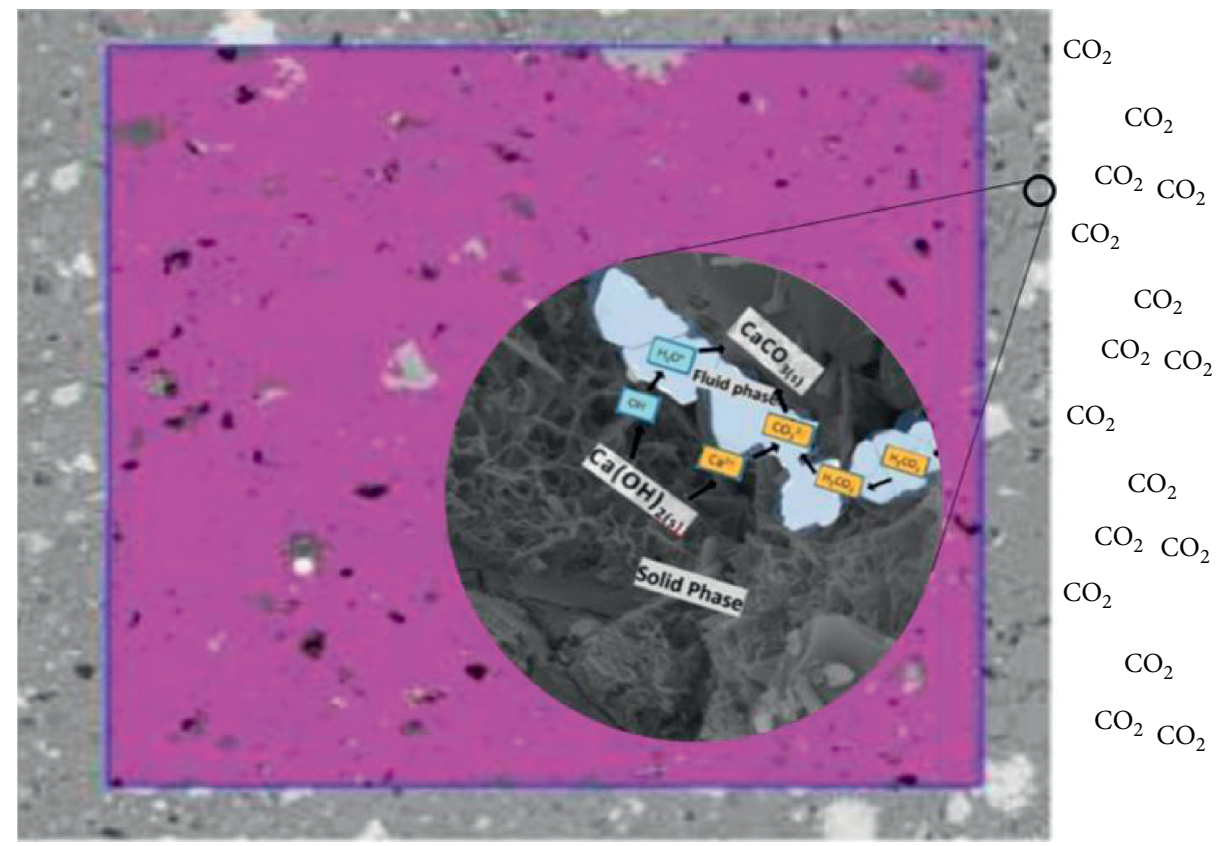

FIGURE 12: Mechanism of carbonation at the pore level and $\mathrm{pH}$ profile along the $\mathrm{CO}_{2}$ infiltration (right).

properties [55]. Apart from $\mathrm{CH}$ and $\mathrm{C}-\mathrm{S}-\mathrm{H}$, further chemical reaction can also occur between dissolved $\mathrm{CO}_{2}$ in the pore solution and other minerals in hardened cement paste, including $\mathrm{C}_{3} \mathrm{~S}$ and $\mathrm{C}_{2} \mathrm{~S}$ and $\mathrm{C}_{3} \mathrm{~A}$. The carbonation of aluminate hydrates is also supposed to be fast. Similar findings were reported by other authors [40]. Inert layers of calcite covering large areas of $\mathrm{C}-\mathrm{S}-\mathrm{H}$ are shown in Figures 9 and 10 , and these prevent the high-density $\mathrm{C}-\mathrm{S}-\mathrm{H}$ from further carbonation.

In the reaction mechanism of OPC concrete, the diffused $\mathrm{CO}_{2}$ reacts with calcium ions from the hydration products of portlandite $\left(\mathrm{Ca}(\mathrm{OH})_{2}\right)$, calcium silicate hydrates (C-S-H), and calcium aluminum silicate hydrate (C-A-S-H), to produce various forms of calcium carbonate $\left(\mathrm{CaCO}_{3}\right)$ [58] according to equations (11) and (12). The high formation rate of $\mathrm{CaCO}_{3}$ by carbonation can fill the pores in concrete structure and densify the matrix as shown in Figure (12) [40, 62]. The microcracks caused by drying shrinkage and long-term shrinkage due to carbonation in GGBS and OPC cement may further result in the diffusion of $\mathrm{CO}_{2}$ and extend the $\mathrm{CO}_{2}$ retention. Carbonation can enhance the microstructure of OPC and GGBS cement through formation of $\mathrm{CaCO}_{3}$, whereas it affects the microstructure of alkali-activated materials [62]: 


$$
\begin{aligned}
\mathrm{Ca}(\mathrm{OH})_{2}+\mathrm{CO}_{2} & \longrightarrow \mathrm{CaCO}_{3}+\mathrm{H}_{2} \mathrm{O} \\
(\mathrm{CaO})_{x} \mathrm{SiO}_{2}\left(\mathrm{H}_{2} \mathrm{O}\right)+x \mathrm{CO}_{2} & \longrightarrow x \mathrm{CaCO}_{3}+\mathrm{SiO}_{2}\left(\mathrm{H}_{2} \mathrm{O}\right)_{y} \\
+ & (z-y) \mathrm{H}_{2} \mathrm{O} .
\end{aligned}
$$

Figures 9 and 10 depict the mineralogical composition and microstructural phase of all concrete mixes after exposure to accelerated and natural carbonation. The dense structure of hydrates shown in the picture (G0) is due to the presence of C-S-H and Portlandite. These compositions further undergo different chemical reactions. As the GGBS cement replacement increases, the reaction rate of $\mathrm{Ca}(\mathrm{OH})_{2}$ with $\mathrm{CO}_{2}$ also increases, which results in the formation of $\mathrm{CaCO}_{3}$ and $\mathrm{H}_{2} \mathrm{O}$. Subsequently, calcium carbonate reacts with carbon dioxide and water, due to the availability of pores for $\mathrm{CO}_{2}$ diffusion, resulting in the formation of pores and calcium bicarbonate $\left(\mathrm{Ca}\left(\mathrm{HCO}_{3}\right)_{2}\right)$ which leads to an increase in concrete permeability. Borges et al. [39] stated that an increased permeability of concrete during carbon dioxide exposure was due to carbonation shrinkage and cracking formed in the slag cement paste after carbonation. However, the overall porosity was reduced due to pore filling by carbonates [29]. In contrast to this fact, the carbonation of OPC concrete yields a denser microstructure because of the formation of significant calcite, which can overcome the shrinkage stress and cracks initiated by CSH decomposition. According to Šavija and Luković (2016), slag-blended cement pastes show a denser microstructure compared to Portland cement paste [40]. As a result of carbonation, porosity of cement paste may change as stated above; this change can be due to a decrease in porosity in the case of OPC paste and increase in porosity in the case of blended cement paste [40]:

$$
\mathrm{CaCO}_{3}+\mathrm{H}_{2} \mathrm{O}+\mathrm{CO}_{2} \leftrightarrow \mathrm{Ca}\left(\mathrm{HCO}_{3}\right)_{2} .
$$

Carbon dioxide $\left(\mathrm{CO}_{2}\right)$ dissolved in aqueous pore solution yields carbonic acid $\left(\mathrm{H}_{2} \mathrm{CO}_{3}\right)$. The reaction between the basic compounds of hydrated cement, namely, calcium hydroxide $\left(\mathrm{Ca}(\mathrm{OH})_{2}\right)$ and calcium silicate hydrate $(\mathrm{C}-\mathrm{S}-\mathrm{H})$ and carbonic acid $\left(\mathrm{H}_{2} \mathrm{CO}_{3}\right)$, produces calcium carbonate $\left(\mathrm{CaCO}_{3}\right)$ and water $\left(\mathrm{H}_{2} \mathrm{O}\right)$. This reaction results in a drop in $\mathrm{pH}$ [63]. The decreasing calcium hydroxide concentration will lead to the dissolution of the other hydrates in concrete cement paste, thus intensifying the carbonation effect. Portlandite reacts with $\mathrm{CO}_{2}$ initially more rapidly than C-S$\mathrm{H}$. However, the rate of reaction decreases with time and is replaced by the C-S-H gel reaction rate due to the formation of various microcrystalline calcium carbonate layers around portlandite hexagonal crystals $[58,64]$. C-A-S-H (calcium aluminate derivatives) shows minimal reaction to $\mathrm{CO}_{2}$ unlike C-S-H (calcium silicate derivatives). In general, the effect of carbonation on strength development of $\mathrm{C}_{3} \mathrm{~A}$ $\left(3 \mathrm{CaCO}_{3} . \mathrm{Al}_{2} \mathrm{O}_{3}\right)$ and $\mathrm{C}_{12} A_{7}\left(12 \mathrm{CaCO}_{3} .7 \mathrm{Al}_{2} \mathrm{O}_{3}\right)$ contribution is insignificant [65].

Figure 12 illustrates the dissolution of $\mathrm{CO}_{2}$ into the pore solution, forming carbonic acid $\left(\mathrm{H}_{2} \mathrm{CO}_{3}\right)$ which is ionized successively to $\mathrm{HCO}^{3-}$ and $\mathrm{CO}_{3}{ }^{2-}$. The results of this reaction are paired: the consumption of $\mathrm{OH}^{-}$ions in pore solution and the formation of solid precipitation of calcite $\left(\mathrm{CaCO}_{3}\right)$ in the pore space. The former decreases the $\mathrm{pH}$ value of the pore solution from around 13.0 to below 9.0, while the latter can fill in the original pore space and strengthen the solid matrix of concrete [55]. The $\mathrm{CH}$ is not the only phase involved in the carbonation reaction with dissolved $\mathrm{CO}_{2}$ in the pore solution; the C-S-H is also the main products from hydration of cement grains and slag particles, including a group of $(\mathrm{CaO}) \mathrm{x}\left(\mathrm{SiO}_{2}\right) \mathrm{y}\left(\mathrm{H}_{2} \mathrm{O}\right) \mathrm{z}$ compounds with $\mathrm{Ca} / \mathrm{Si}$ ratios involved in the carbonation reaction. In simplistic way, this reaction is shown in equation (12). However, due to the very low solubility of $\mathrm{C}-\mathrm{S}-\mathrm{H}$ in the pore solution, the effect of C-S-H carbonation on the $\mathrm{pH}$ value of the pore solution is considered to be weak.

\section{Conclusions}

This study has investigated the influence of carbon dioxide exposure on the properties of concrete cast with ordinary Portland cement (OPC) and various percentages of GGBS. The properties studied were carbonation rate, depth of carbonation, and mechanical and microstructural properties of concrete. Concrete cubes cast with OPC, and various percentages of GGBS $(0 \%, 30 \%, 50 \%$, and $70 \%)$ were subject to natural (indoor) and accelerated carbonation exposure. The following conclusions can be made based on the experimental results obtained:

(i) The carbonation coefficient was found to increase with increase in GGBS replacement level. The replacement of ordinarily Portland cement (OPC) by GGBS leads to an increase in the carbonation depth of concrete under the same experimental conditions.

(ii) For all given concrete groups and testing time, concretes exposed to natural carbonation (indoor) had lower carbonation rates than those exposed to accelerated carbonation. Low carbonation rates were displayed in concretes with low permeabilities, particularly in concretes made from 100\% OPC. Rate of carbonation was more sensitive to change in \%GGBS rather than extending the testing time.

(iii) The calcite crystallites for concrete samples exposed to accelerated carbonation were often seen as irregular in shape and become denser as the slag replacement increased compared to samples exposed to natural carbonation. The carbonation of OPC concrete yields a denser microstructure than blended Portland cement because of the formation of significant calcite, in both exposure conditions.

(iv) The above proposed mathematical model between carbonation depth and exposure duration can be used as input for predicting and evaluating the response of OPC and slag-blended Portland cement concrete subjected to both natural carbonation and 
accelerated carbonation. From the empirical carbonation rate prediction model, the trend observed regarding to the duration of carbonation exposure with and without GGBS is generally similar for natural and accelerated carbonation exposure. Furthermore, the carbonation depth of concrete with $0 \%, 30 \%$, and $50 \%$ GGBS content after $56 \mathrm{~d}$ of accelerated carbonation exposure was nearly twice that of 1-year natural carbonation exposure.

(v) The presence of significant calcite formation is intensified for concrete exposed to accelerated carbonation compared to natural carbonation. Furthermore, increasing \%GGBS leads to the formation of a coarser microstructure and results in a possible increment in concrete porosity.

\section{Data Availability}

The research data used to support the finding of this study are described and included in the article. Furthermore, some of the data used in this study are also supported by providing references as described in the article.

\section{Conflicts of Interest}

The authors declare that they have no conflicts of interest.

\section{Authors' Contributions}

All the authors contributed substantially to all aspects of this article. All the authors read and approved the final manuscript.

\section{Acknowledgments}

Experimental work described in this paper was financially supported by the Program for Innovative Research Team of Education Ministry of China (IRT_16R67) and Thousand Talents Plan in Henan Province (ZYQR201912029).

\section{References}

[1] L. Qin, X. Gao, and T. Chen, "Influence of mineral admixtures on carbonation curing of cement paste," Construction and Building Materials, vol. 212, pp. 653-662, 2019.

[2] N. De Belie, M. Soutsos, and E. Gruyaert, Eds., Working Group 4, Springer International Publishing, vol. 25, , 2018.

[3] M. Á. Sanjuán, C. Andrade, P. Mora, and A. Zaragoza, "Carbon dioxide uptake by mortars and concretes made with portuguese cements," Applied Science, vol. 15, 2020.

[4] M. Á. Sanjuán, E. Estévez, and C. Argiz, "Carbon dioxide absorption by blast-furnace slag mortars in function of the curing intensity," Energies, vol. 12, no. 12, p. 2346, 2019.

[5] L. Mo and D. K. Panesar, "Accelerated carbonation-a potential approach to sequester $\mathrm{CO} 2$ in cement paste containing slag and reactive $\mathrm{MgO}$," Cement and Concrete Composites, vol. 43, pp. 69-77, 2013.

[6] F. Xi, S. J. Davis, P. Ciais et al., "Substantial global carbon uptake by cement carbonation," Nature Geoscience, vol. 9, no. 12 , pp. $880-883,2016$.
[7] C. Shi, A. F. Jiménez, and A. Palomo, "New cements for the 21st century: the pursuit of an alternative to Portland cement," Cement and Concrete Research, vol. 41, no. 7, pp. 750-763, 2011.

[8] M. Á. Sanjuán, C. Andrade, P. Mora, and A. Zaragoza, "Carbon dioxide uptake by cement-based materials: a Spanish case study," Applied Sciences, vol. 10, no. 1, p. 339, 2020.

[9] S. Goñi, M. T. Gaztañaga, and A. Guerrero, "Role of cement type on carbonation attack," Journal of Materials Research, vol. 17, no. 7, pp. 1834-1842, 2002.

[10] M. Otieno, J. Ikotun, and Y. Ballim, "Experimental investigations on the effect of concrete quality, exposure conditions and duration of initial moist curing on carbonation rate in concretes exposed to urban, inland environment," Construction and Building Materials, vol. 246, Article ID 118443, 2020.

[11] A. M. Diab, H. E. Elyamany, and A. E. M. Abd Elmoty, "Effect of mix proportions, seawater curing medium and applied voltages on corrosion resistance of concrete incorporating mineral admixtures," Alexandria Engineering Journal, vol. 50, no. 1, pp. 65-78, 2011.

[12] M. Nevile, Properties of Concrete, Longman Singapore, Great Britain, UK, 3rd edition, 1994.

[13] M. Elsalamawy, A. R. Mohamed, and E. M. Kamal, "The role of relative humidity and cement type on carbonation resistance of concrete," Alexandria Engineering Journal, vol. 58, no. 4, pp. 1257-1264, 2019.

[14] A. Morandeau, M. Thiéry, and P. Dangla, "Impact of accelerated carbonation on OPC cement paste blended with fly ash," Cement and Concrete Research, vol. 67, pp. 226-236, 2015.

[15] S. K. Roy, K. B. Poh, and D. o. Northwood, "Durability of concrete-accelerated carbonation and weathering studies," Building and Environment, vol. 34, no. 5, pp. 597-606, 1999.

[16] V. Shah, K. Scrivener, B. Bhattacharjee, and S. Bishnoi, "Changes in microstructure characteristics of cement paste on carbonation," Cement and Concrete Research, vol. 109, pp. 184-197, 2018.

[17] G. Villain, M. Thiery, and G. Platret, "Measurement methods of carbonation profiles in concrete: thermogravimetry, chemical analysis and gammadensimetry," Cement and Concrete Research, vol. 37, no. 8, pp. 1182-1192, 2007.

[18] R. Kurda, J. de Brito, and J. D. Silvestre, "Carbonation of concrete made with high amount of fly ash and recycled concrete aggregates for utilization of $\mathrm{CO} 2$," Journal of $\mathrm{CO}_{2}$ Utilization, vol. 29, pp. 12-19, 2019.

[19] Nevile, M. Adam, Concrete Technology, Longman Singapore, Great Britain, UK, 2nd ed. edition, 2010.

[20] G. K. Glass, Reinforcement Corrosion, Advanced Concrete Technology, Elsevier, Amsterdam, Netherlands, pp. 1-27, 2003.

[21] G. K. Glass, "Deterioration of steel reinforced concrete," Comprehensive Structural Integrity, Elsevier, Amsterdam, Netherlands, pp. 321-350, 2003.

[22] S. Goni, M. T. Gaztanaga, and A. Guerrero, "Role of cement type on carbonation attack," Journal of Materials Research, vol. 17, no. 7, p. 9, 2002.

[23] J. H. M. Visser, “Accelerated carbonation testing of mortar with supplementary cementing materials-limitation of the acceleration due to drying," Heron, vol. 18, 2012.

[24] T. Bakharev, J. G. Sanjayan, and Y.-B. Cheng, "Resistance of alkali-activated slag concrete to carbonation," Cement and Concrete Research, vol. 31, no. 9, pp. 1277-1283, 2001. 
[25] K. Behfarnia and M. Rostami, "An assessment on parameters affecting the carbonation of alkali-activated slag concrete," Journal of Cleaner Production, vol. 157, pp. 1-9, 2017.

[26] Z. Li and S. Li, "Carbonation resistance of fly ash and blast furnace slag based geopolymer concrete," Construction and Building Materials, vol. 163, pp. 668-680, 2018.

[27] C. Andrade, "Evaluation of the degree of carbonation of concretes in three environments," Construction and Building Materials, vol. 230, Article ID 116804, 2020.

[28] C.-Q. Lye, R. K. Dhir, and G. S. Ghataora, "Carbonation resistance of GGBS concrete," Magazine of Concrete Research, vol. 68, no. 18, pp. 936-969, 2016.

[29] A. Gholizadeh-Vayghan, A. Bellinkx, R. Snellings, B. Vandoren, and M. Quaghebeur, "The effects of carbonation conditions on the physical and microstructural properties of recycled concrete coarse aggregates," Construction and Building Materials, vol. 257, Article ID 119486, 2020.

[30] L. Mo, "Accelerated carbonation and performance of concrete made with steel slag as binding materials and aggregates," Cement and Concrete Composites, vol. 8, 2017.

[31] China Building Materials Science Research Institute, National Standard of The People's Republic of China (GB 175-2007), China Building Materials Science Research Institute, Beijing, China, 2007.

[32] RILEM, "CPC-18 Measurement of hardened concrete carbonation depth," Materials and Structures, vol. 3, 1988.

[33] Ministry of Housing and Urban-Rural Construction of the People's Republic of China, Standard for Test Method of Long Term Performance and Durability of Ordinary Concrete (GB/T 50082-2009), Ministry of Housing and Urban-Rural Construction of the People's Republic of China, Beijing, China, 2010.

[34] China Building Materials Science Research Institute, Testing Methods for Long-Term and Long-Lasting Performance of Ordinary concrete, China Building Materials Science Research Institute, Beijing, China, 1985.

[35] J. Wang, H. Xu, D. Xu et al., "Accelerated carbonation of hardened cement pastes: influence of porosity," Construction and Building Materials, vol. 225, pp. 159-169, 2019.

[36] Hydrocarbont, M. (n.d.). CPC-18 Measurement of hardened concrete carbonation depth, 3 .

[37] N. Li, N. Farzadnia, and C. Shi, "Microstructural changes in alkali-activated slag mortars induced by accelerated carbonation," Cement and Concrete Research, vol. 100, pp. 214-226, 2017.

[38] P. Basu, R. Chandra Gupta, and V. Agrawal, "Effect of carbonation on the mechanical and durability properties of sandstone modified self-compacting concrete," Materials Today: Proceedings, vol. 32, p. 686, 2020.

[39] P. H. R. Borges, J. O. Costa, N. B. Milestone, C. J. Lynsdale, and R. E. Streatfield, "Carbonation of $\mathrm{CH}$ and $\mathrm{C}-\mathrm{S}-\mathrm{H}$ in composite cement pastes containing high amounts of BFS," Cement and Concrete Research, vol. 40, no. 2, pp. 284-292, 2010.

[40] B. Šavija and M. Luković, "Carbonation of cement paste: understanding, challenges, and opportunities," Construction and Building Materials, vol. 117, pp. 285-301, 2016.

[41] M. Thiéry, P. Faure, A. Morandeau et al., "Effect of carbonation on the microstructure and moisture properties of cement - based materials," Materials and Methods, vol. 8, 2011.

[42] Z. Shi, C. Shi, S. Wan, N. Li, and Z. Zhang, "Effect of alkali dosage and silicate modulus on carbonation of alkali-activated slag mortars," Cement and Concrete Research, vol. 113, pp. 55-64, 2018.

[43] Q. Liu, J. Liu, and L. Qi, "Effects of temperature and carbonation curing on the mechanical properties of steel slag-cement binding materials," Construction and Building Materials, vol. 124, pp. 999-1006, 2016.

[44] R. Bucher, M. Cyr, and G. Escadeillas, "Carbonation of blended binders containing metakaolin," in Calcined Clays for Sustainable Concrete, K. Scrivener and A. Favier, Eds., vol. 10, pp. 27-33, Springer, Netherlands, Dordrecht, 2015.

[45] Y. Gao, L. Cheng, Z. Gao, and S. Guo, "Effects of different mineral admixtures on carbonation resistance of lightweight aggregate concrete," Construction and Building Materials, vol. 43, pp. 506-510, 2013.

[46] L. Black, Low Clinker Cement as a Sustainable Construction Material, Sustainability of Construction Materials, Elsevier, Amsterdam, Netherlands, 2016.

[47] K. Sisomphon and L. Franke, "Carbonation rates of concretes containing high volume of pozzolanic materials," Cement and Concrete Research, vol. 37, no. 12, pp. 1647-1653, 2007.

[48] V. Shah and S. Bishnoi, "Carbonation resistance of cements containing supplementary cementitious materials and its relation to various parameters of concrete," Construction and Building Materials, vol. 178, pp. 219-232, 2018.

[49] E. Gruyaert, P. Van den Heede, and N. De Belie, "Carbonation of slag concrete: effect of the cement replacement level and curing on the carbonation coefficient - effect of carbonation on the pore structure," Cement and Concrete Composites, vol. 35, no. 1, pp. 39-48, 2013.

[50] H. Zhao, W. Sun, X. Wu, and B. Gao, "The effect of the material factors on the concrete resistance against carbonation," KSCE Journal of Civil Engineering, vol. 22, no. 4, pp. 1265-1274, 2018.

[51] ACI Committee 318; American Concrete Institute; International Organization for Standardization, Building Code Requirements for Structural Concrete (ACI 318M-08) and Commentary, American Concrete Institute, Farmington Hills, Mich, 2008.

[52] A. W. Beeby and R. S. Narayanan, Designers' Guide to EN 1992-1-1 and EN 1992-1-2 Eurocode 2: Design of Concrete Structures:, General Rules and Rules for Buildings and Structural Fire Design (Repr.), Telford, London, 2013.

[53] China Standardization Administration of China, National Standard of The People's Republic of China, China Standardization Administration of China, Beijing, China, 2008.

[54] K. Li, Z. Chen, and H. Lian, "Concepts and requirements of durability design for concrete structures: an extensive review of CCES01," Materials and Structures, vol. 41, no. 4, pp. 717-731, 2008.

[55] K. Li, Durability Design of Concrete Structures: Phenomena, Modelling and Practice, Wiley, Solaris South Tower, Singapore, 2016.

[56] L.-O. Nilsson, "Interaction between microclimate and concrete-a prerequisite for deterioration," Construction and Building Materials, vol. 10, no. 5, pp. 301-308, 1996.

[57] V. G. Papadakis, C. G. Vayenas, and M. N. Fardis, "Physical and chemical characteristics affecting the durability of concrete," ACI Materials Journal, vol. 88, no. 2, 1991.

[58] M. Á. Sanjuán, E. Estévez, C. Argiz, and D. D. Barrio, "Effect of curing time on granulated blast-furnace slag cement mortars carbonation," Cement and Concrete Composites, vol. 90, pp. 257-265, 2018.

[59] B. S. Divsholi, T. Y. D. Lim, and S. Teng, "Durability properties and microstructure of Ground granulated blast furnace 
slag cement concrete," International Journal of Concrete Structures and Materials, vol. 8, no. 2, pp. 157-164, 2014.

[60] R. K. Dhir, P. C. Hewlett, and Y. N. Chan, "Near-surface characteristics of concrete: prediction of carbonation resistance," Magazine of Concrete Research, vol. 41, no. 148, pp. 137-143, 1989.

[61] M. A. Sanjuán, A. Piñeiro, and O. Rodríguez, "Aplicaciones y limitaciones del coeficiente $\mathrm{K}$ de eficacia de la adición de escoria de horno alto en el hormigón," Materiales de Construcción, vol. 61, no. 302, pp. 303-313, 2011.

[62] J. Zhang, C. Shi, N. Li, Z. Zhang, and N. Farzadnia, Carbon Dioxide Sequestration by Alkali-Activated Materials, Carbon Dioxide Sequestration in Cementitious Construction Materials, Elsevier, Amsterdam, Netherlands, pp. 279-298, 2018.

[63] V.-L. Ta, S. Bonnet, T. Senga Kiesse, and A. Ventura, "A new meta-model to calculate carbonation front depth within concrete structures," Construction and Building Materials, vol. 129, pp. 172-181, 2016.

[64] T. P. Hills, F. Gordon, N. H. Florin, and P. S. Fennell, "Statistical analysis of the carbonation rate of concrete," Cement and Concrete Research, vol. 72, pp. 98-107, 2015.

[65] D. Zhang, Z. Ghouleh, and Y. Shao, "Review on carbonation curing of cement-based materials," Journal of $\mathrm{CO}_{2}$ Utilization, vol. 21, pp. 119-131, 2017. 